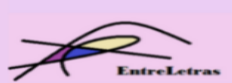

REVISTA ENTRELETRAS (ARAGUAÍNA), V. 12, N. 3, SET./DEZ. 2021 (ISSN 2179-3948 - ONLINE)

\title{
CANUDOS/PARAGUAI: REGRESSOS FICCIONAIS DAS GUERRAS
}

\section{CANUDOS/PARAGUAI: REGRESOS FICCIONALES DE LAS GUERRAS}

\section{DOI 10.20873/uft2179-3948.2021v12n3p104-114}

\section{Adenilson de Barros de Albuquerque ${ }^{1}$}

Resumo: Este artigo analisa os romances históricos Canudos de Antônio Conselheiro (2018), de Hélio de Araújo, e Paraízo-Paraguay (2019), de Marcelo Labes. O objetivo é destacar as principais confluências e/ou novidades que essas publicações recentes da literatura brasileira apresentam em relação a uma longa lista de romances latino-americanos - sobre os respectivos temas da Guerra de Canudos (1896-1897) e da Guerra do Paraguai (1864-1870) - estudados por Albuquerque e Fleck (2015) e Albuquerque (2020).

Palavras-chave: literatura comparada; romance histórico; narrativa canudense; palavra armada; América Latina.

Resumen: Este artículo analiza las novelas históricas Canudos de Antônio Conselheiro (2018), de Hélio de Araújo, y Paraízo-Paraguay (2019), de Marcelo Labes. El objetivo es destacar las principales confluencias y/o novedades que esas publicaciones recientes de la literatura brasileña presentan con relación a una larga lista de novelas latinoamericanas - sobre los respectivos temas de la Guerra de Canudos (1896-1897) y de la Guerra del Paraguay (18641870) - estudiadas por Albuquerque y Fleck (2015) y Albuquerque (2020).

Palabras claves: literatura comparada; novela histórica; narrativa canudense; palabra armada; América Latina.

\section{Introdução}

Em pesquisa relacionada aos romances históricos que tematizam a Guerra de Canudos (1896-1897), inicialmente apresentada como dissertação de mestrado (ALBUQUERQUE, 2013) e posteriormente reconfigurada para publicação em livro (ALBUQUERQUE; FLECK, 2015), listou-se obras surgidas num período que percorre o final do século XIX até a primeira metade do século XXI.

Entre as principais conclusões, ficou, em linhas gerais, a de que Os sertões (1902), de Euclides da Cunha, representa a primeira surpresa, o contato intelectualmente inaugural entre dois Brasis; La guerra del fin del mundo (1981), de Mario Vargas Llosa, mostra-se como o intento de trazer ficcionalmente a história da guerra em suas múltiplas perspectivas; $O$ pêndulo

\footnotetext{
${ }^{1}$ Doutor em Letras pela Unioeste. Professor EBTT do Instituto Federal do Paraná Campus Umuarama. E-mail: adenilson.albuquerque@ifpr.edu.br ORCID 0000-0003-0090-2672
} 


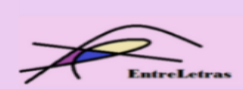

de Euclides (2009), de Aleilton Fonseca, incursiona pela história, pelas vozes do passado e do presente, pela Canudos de ontem e de hoje, na proposta crítica de um encontro amigável entre o litoral e o sertão, ainda distantes para além da geografia.

Assim, em alguma medida devedoras e posteriores à obra euclidiana,

\begin{abstract}
a representatividade da surpresa de um contato avassalador entre dois mundos é ampliada a partir do pluriperspectivismo do romance de Vargas Llosa, numa leitura metonímica da América Latina. Na leitura da narrativa canudense de Aleilton Fonseca, deparamo-nos com a aproximação entre mundos ainda em muitos aspectos distantes, porém bastante próximos do "entendimento" pacífico e criador, quando resolvem dialogar e rever questões que ficaram suspensas, numa busca de ultrapassar conflitos historicamente estabelecidos. (ALBUQUERQUE; FLECK, 2015, p. 179).
\end{abstract}

Será a partir desses encaminhamentos possíveis, desses modos de se ficcionalizar a guerra, que este artigo, num primeiro momento, voltará a atenção para o livro Canudos de Antônio Conselheiro (2018), de Hélio de Araújo, talvez a mais recente reelaboração literária entre as narrativas canudenses de que se tem notícia.

Em segundo lugar, dessa vez tendo como principal embasamento a pesquisa que resultou em tese de doutorado (ALBUQUERQUE, 2020) - na qual estão reunidos dezenas de romances históricos que tematizam a Guerra do Paraguai (1864-1870), publicados por autores paraguaios, argentinos, brasileiros e uruguaios -, será considerado o livro Paraízo-Paraguay (2019), de Marcelo Labes. O intuito está em discorrer sobre as semelhanças e/ou desvios que o romance apresenta dentro dos limites do ficou entendido por "palavra armada", que

no âmbito da ficção está empregada nos romances históricos como elemento devedor
da "palavra armada" pela historiografia. Essa postura manifesta-se na exposição das
causas e consequências dos conflitos bélicos e, especialmente, na constituição das
vozes narrativas. Apresenta-se, por sua vez, geralmente preconceituosa, ressentida e
resulta em certo desinteresse ficcional em relação aos encontros e contrastes
responsáveis pela formação híbrida latino-americana, ricamente substanciada no que
foi e representa a Guerra Grande para o continente. (ALBUQUERQUE, 2020, p. 14).

Nota-se, nessa exposição, que a temática das duas guerras em destaque foi e continua sendo motivo de interesse tanto para investigadores acadêmicos quanto para romancistas. Os eventos bélicos, seja entre países da América Latina seja no âmbito geográfico de uma área inóspita do Brasil, pressupõem muitas alternativas de ficcionalização, variados caminhos para voltar ao passado, atualizá-lo por meio de velhas ou de novas palavras, a depender do repertório, das escolhas e dos posicionamentos de cada autor.

O paranaense de nascimento Hélio de Araújo, que desde bebê reside em Pernambuco, e o catarinense Marcelo Labes estão, com suas obras evidenciadas neste estudo, entre os escritores que resolveram retornar às questões bélicas, ainda hoje repletas de pontos obscuros, 


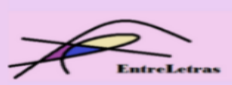

REVISTA ENTRELETRAS (ARAGUAÍNA), V. 12, N. 3, SET./DEZ. 2021 (ISSN 2179-3948 - ONLINE)

culpas, mal-entendidos, ou simplesmente maldades escancaradas da diplomacia humana, dos poderes herdados por poucos e executados por tantos em nome da ordem e das leis.

Diante do exposto, passa-se a seguir a leitura dos romances brasileiros selecionados, recentes revisitações ao passado que, de uma maneira ou de outra, insiste em rondar as memórias, os escritos, as histórias.

\section{Canudos}

Canudos de Antônio Conselheiro, romance de Hélio de Araújo, vem a público em dezembro de 2018. Em matéria relativa ao lançamento do livro, há o seguinte destaque: “Ao mesmo tempo em que traz um relato histórico da guerra, a obra também evidencia a figura do líder religioso Antônio Conselheiro, enquanto um homem que lutava por uma sociedade mais justa, igual e livre de opressões.” (G1 PETROLINA, 2018, s. p.). Nas palavras de Aroldo Ferreira Leão (2020, p. 6), a atenção a tantos enfoques e concepções faz de Hélio Araújo "uma criatura plural, menino sondando o infinito de suas próprias averiguações e ressurgimentos, semblante contemplando as sutilezas dos espaços que o rondam, confissão delineando no tempo a magia dos homens sinceros, simples, singulares."

Essas considerações direcionam escritor e obra para uma perspectiva que, no conjunto das narrativas canudenses, estará em concordância com as leituras que veem no arraial conselheirista a principal vítima do poder republicano no desencadear e no desenrolar da guerra.

Disposto em capítulos, o romance divide-se em: O Conselheiro; O Choque de Maceté; O Arraial; O Fogo de Uauá; A batalha na lagoa; A expedição de Moreira Cesar; A quarta expedição; Os Reforços; O Extermínio. Na feitura do texto, o narrador apresenta-se implicitamente como um contador de histórias letrado que reúne materiais bibliográficos para formular uma narrativa cronológica da guerra. Baseado, assim, no que leu e na imaginação, o narrador volta-se aos episódios da vida de Antônio Conselheiro e da Guerra de Canudos no contexto das últimas três décadas do século XIX. Inicia-se com a vida e as andanças do peregrino, segue para a formação e desenvolvimento do arraial de Canudos e, mais destacadamente, relata as expedições militares que rumaram para o sertão baiano no decorrer de quase um ano.

Entre as citações diretas inseridas ao longo do texto, estão trechos escritos por Euclides da Cunha (ARAÚJO, 2020, p. 63); José Calasans (ARAÚJO, 2020, p. 90, p. 107) e Patativa do Assaré (ARAÚJO, 2020, p. 90-91), todas elas devidamente elencadas nas referências dispostas nas páginas finais do livro. Verifica-se ainda a utilização de outros recursos paratextuais após 


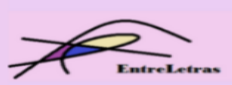

o final da história, na reprodução de seis fotos referentes às imediações de Canudos nos tempos da guerra, todas elas atribuídas a Flávio de Barros. (ARAÚJO, 2020, p. 109-111).

O narrador letrado, conhecedor do mundo sertanejo também por experiência, a busca por evidenciar autenticidade no relato lançando mão de uma pesquisa explicitada e de uma narrativa crítica, verossímil e linear levam Canudos de Antônio Conselheiro aos pressupostos do romance histórico contemporâneo de mediação, que confere "um tom de autenticidade ao eventos históricos renarrativizados, a partir de perspectivas periféricas, ancoradas em narradores-personagens antes vistos como secundários ou esquecidos pelo discurso historiográfico." (FLECK, 2017, p. 110). A voz enunciadora do romance em questão não traz a narrativa para o tempo presente, ou seja, evita anacronismos ao não participar dos eventos narrados e não os transporta para a apreciação de comentaristas atuais. Nas poucas participações de personagens ficcionalizadas, contudo, será uma senhora sertaneja que virá para o primeiro plano em diferentes momentos da narrativa.

Dona Mariazinha, assim chamada a personagem, não está entre os moradores de Canudos, mas vive nas redondezas, tem conhecimentos dos conflitos e até se depara e conversa com conselheiristas que passam pela sua residência, num sítio à beira da estrada. Foi ela que "tirou uma chaleira de café do fogo, coou, colocou açúcar, encheu duas xícaras e foi oferecer àquela família simples [que seguiria] a passos firmes ao encontro da nova cidade" (ARAÚJO, 2020 , p. 33). Percebia "o aumento do fluxo de caminhantes rumando em direção da cidadela de Antônio Conselheiro. Eram ambulantes, trabalhadores artesanais, pequenos comerciantes, desocupados, sem-terra, sem-abrigo, sem-esperança.” (ARAÚJO, 2020, p. 39). Ouviu "aterrorizada, o tiro retumbante do canhão, as rajadas arrepiantes das metralhadoras e a barulheira contínua da fuzilaria." (ARAÚJO, 2020, p. 47). Mais para o final da narrativa,

Dona Mariazinha, da sua janela, lamentava pelos soldados feridos com gravidade e chorava pela gente sertaneja que morreu pela causa canudense. [...] Como não repararam que lá evitavam prostituição e bebida alcoólica e que Conselheiro não servia a nenhum partido político? Porquê matar, queimar, destruir, qual é o sentido de tantas barbaridades? Porque não aguardaram mais alguns dias se a rendição seria certa, pela sede ou fome, já que todas as saídas estavam bloqueadas? (ARAÚJO, 2020, p. 104).

Nos encontros e nas sentenças dessa personagem estão, por um lado, um pouco da vida sertaneja, do acolhimento como costume ancestral. Por outro lado, aparece a indignação, a certeza de que as coisas poderiam acontecer de modo diferente se houvesse interesse por parte do poder governamental instituído, da Igreja Católica e mesmo das sociedades civis “civilizadas” da época. Não houve grandes esforços para se evitar os enfrentamentos bélicos. A visita/missão do frei João Evangelista de Monte Marciano (ARAÚJO, 2020, p. 25-29) não 


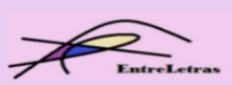

favoreceu Antônio Conselheiro e o arraial, formado por "aqueles que chegavam desanimados após experimentarem anos de privações variadas." (ARAÚJO, 2020, p. 24).

Chamam a atenção na obra momentos como a menção à professora, “jovem educadora de um município próximo, que foi morar e lecionar no arraial, residindo numa rua que ficou conhecida como Rua da Professora. Na escola sob a responsabilidade dela, a garotada tinha aula todos os dias" (ARAÚJO, 2020, p. 30); ou o dia em que o Conselheiro caminha pelas casas e, de uma delas, "saiu depois de rápida conversa, deixando a dona-de-casa manejando colher de pau, mexendo o feijão com toucinho que fervia na panela de barro, transbordando de felicidade pela inusitada visita." (ARAÚJO, 2020, p. 52). O apreço pela educação e o afeto, além da religiosidade costumeira, também se revelam essenciais e constantes entre aqueles moradores de Canudos.

No decorrer da guerra, "Pajeú e sua turma seguiram os sodados pelas caatingas, vigiando pelos penhascos, dentre as moitas e armaram tocaias que resultaram em mais baixas dos dois lados." (ARAÚJO, 2020, p. 46). Essa passagem tem relação com as ações conselheiristas que, segundo Wellington Freire (2017, p. 71), após o aprendizado obtido no confronto de Uauá, corrigiram os erros e "não os repetiria nas três ações de combate posteriores." Nesse estudo comparado sobre as táticas e estratégias utilizadas pelos sertanejos e sua relação com diversas batalhas ocorridas na Antiguidade, na Idade Média, na Modernidade ou posteriores a Canudos, o autor demonstra o seguinte: "Se o inconsistente exército brasileiro usou armas e táticas que encontrariam sua mais ampla expressão nas guerras das décadas iniciais do século XX, mais modernos ainda foram os jagunços e por isso quase destroçaram o inimigo [...].” (FREIRE, 2017, p. 97).

Em uma das conclusões da narrativa, lê-se o seguinte:

Tudo isso poderia ter sido evitado, mas o Governo Federal, ajudado pelos jornais, incutiu que Canudos era um antro de rebeldes, ignorantes, fanáticos, jagunços, bandidos, insanos, monarquistas, selvagens, inimigos do Brasil. O gravíssimo erro político atingiu também os soldados defensores das instituições republicanas que experimentaram exaustivas caminhadas com armamento, munição e outros apetrechos nos próprios ombros, dormindo ao relento ou sob tendas, acordando com fardas sujas e amarrotadas, sentando em pedras, troncos e no chão, enfrentando sol quente, sede e a fraqueza aguçada pela fome. (ARAÚJO, 2020, p. 105).

Essas palavras dialogam de alguma maneira com o que percebeu Euclides da Cunha em Os sertões: "Eram, realmente, fragílimos aqueles pobres rebelados [...] Entretanto enviamolhes o legislador Comblain; e esse argumento único, incisivo, supremo e moralizador - a bala." (CUNHA, 1987, p. 140). A fragilidade - a história e a literatura estão aí para demonstrar - nem de longe era física ou moral. O que faltou foi compreensão e desejo de contribuir para que ao 


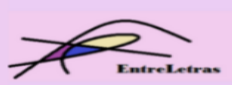

sertão também fossem levados direitos mínimos de educação, cultura, lazer e trabalho, artigos ainda escassos no Brasil atual, inclusive nos contextos urbanos.

No âmbito pessoal, Canudos de Antônio Conselheiro "consolida Hélio como um escritor que consegue dar leveza a episódios sangrentos, articulando história e literatura, despertando o prazer de ler." (LIMA, 2020, p. 116). Em termos de posicionamento em relação às narrativas canudenses, é uma abra que transita pela ótica dos vencidos, que preza pela cronologia dos fatos, pela visita ao passado, sem a pretensão de grandes inovações estéticas.

\section{Paraguai}

Paraízo-Paraguay (2019), de Marcelo Labes, não por acaso já é um romance consagrado pela crítica (Prêmio São Paulo de Literatura 2020 e segundo lugar no Prêmio Machado de Assis da Fundação Biblioteca Nacional - 2019). Disposto em 21 capítulos, com alternâncias de vozes narrativas, a obra acompanha as personagens de uma família num período que vai de meados do século XIX até os tempos muito próximos da primeira edição do livro. Não é uma narrativa unicamente destinada a retratar a Guerra do Paraguai, mas o evento histórico perpassa o texto de modo basilar: a personagem Wilhelm (forasteiro alemão) esteve na guerra, sobreviveu como pode e de lá, após a batalha de Acosta $\tilde{N} u$, trouxe para o Brasil uma criança, o "índio" José/Joseph/Pepe, bisavô da personagem Udo que, devido às palavras e aos silêncios da família marcada por solidões, loucuras e exploração, viaja ao país vizinho em busca de notícias - quem sabe alguma herança - do antepassado que voltou para a terra natal poucos anos após o nascimento da personagem Olga (filha de Pepe e Frieda; casada com Hubert; mãe de Hans que é casado com Anna; avó de Martha e Udo), voz enunciadora primordial no romance:

\footnotetext{
Olga perdeu a memória, os modos, os freios e a dignidade - desde a morte de Hubert que está assim -, mas nunca perdeu a chave que carrega nas mãos e segura com tanta força que é possível ver saltadas as veias de seus braços, os músculos convictos. É uma chave de lata, simples, barata. Até pouco tempo atrás, ninguém havia se perguntado o que ela abria. Foi quase por acidente que se recordou uma tal história dos tempos de guerra. Não, nunca houve guerra no Paraízo, a não ser por causa de terrenos íngremes e pedregosos quando no momento que se quis dividi-los e colocalos à venda. Mas houve sim, que se saiba, uma guerra na Europa, aquele lugar que por essa época já quase ninguém lembrava direito onde ficava, ninguém sabia apontar no mapa e tampouco havia alguém no Paraízo que houvesse conseguido chegar lá. (LABES, 2021, p. 13).
}

Antes de morrer, por cinco dias seguidos, a personagem Olga que era considerada distante do "mundo real", pois não comandava mais nem o corpo nem as ideias, resolve falar. Conta uma longa história sobre ela, o marido, os seus pais, e sobre a personagem 


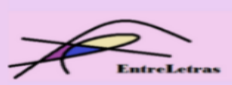

Wilhelm/Guilherme que um dia chegou ao Paraízo e de lá foi mandado para a guerra pelo administrador do local, que viu nele uma ameaça e uma oportunidade de enviar outra pessoa, ao invés de um filho, como voluntário da Pátria, prática comum no território nacional entre os homens de poder. "Cada um daqueles soldados acampados, cada voluntário, sem tirar nem pôr, os pobres coitados iam lutar na guerra no lugar dos filhos dos alemães ricos”. (LABES, 2021, p. 80). É por intermédio da personagem Wilhelm que muitos episódios da guerra são narrados pela voz de Olga no Paraízo que

é um bairro, quase um distrito, ou um gueto, se assim se preferir, distante da cidade e perto do mato, dos morros, dos córregos, das cobras peçonhentas, onde vivem pessoas que não falavam português até poucos anos atrás. Fica ao sul do que foi o centro da antiga colônia. Mesmo depois de alçada a município, a colônia nunca deixou de existir - hoje é uma grande cidade, mas é ainda uma vila: cresce sem deixar de ser. Onde anos atrás se dizia que era cidade, agora se diz centro. Paraízo fica tão distante do centro que muitas pessoas que lá vivem nunca foram à cidade. Muitas pessoas dali também nunca viram o mar. (LABES, 2021, p. 9).

Inesperadamente, transitando pelo "alemão desconhecido pelos ouvintes, um alemão gramatical, perfeito, antigo e natural" (LABES, 2021, p. 39), português e guarani (o romance está essencialmente em português, mas indica quando a personagem muda de idioma), Olga intriga os parentes - talvez à exceção do pastor que acompanha grande parte dos últimos dias da velha senhora -, acostumados a poucas palavras e à solidão. A personagem Anna, nora de Olga, pergunta ao marido: "E se for verdade, Hans? E se tudo isso tiver acontecido? Deus me livre se alguém ouvir uma loucura dessas.” (LABES, 2021, p. 57).

Entre os eventos da guerra, relata a velha personagem que o administrador da colônia (hoje parte de Blumenau-SC) não sabia "o motivo exato do confronto, mas tudo indica que o presidente desse país vizinho invadiu as terras do Império, vindo Sua Majestade a ofender-se de maneira inimaginável e nunca antes vista.” (LABES, 2021, p. 62). Essa postura ficcional é uma das chaves para se compreender que a narrativa não tem grandes preocupações em discutir infinitamente sobre as causas e os culpados do conflito, como o fazem muitos romances históricos. Questões relacionadas à historiografia (não só a da Guerra do Paraguai) aparece em vários episódios, mas cuidadosamente selecionados para a verossimilhança e o encadeamento da obra, sem deixar, contudo, de apresentar a repulsa pela personagem histórica Conde d'Eu, no ocorrido na batalha do dia 16 de agosto de 1869, em Acosta $\tilde{N} u$.

Todos mortos, todos mortos, gritava o Conde, genro do Imperador e marido da Princesa, e enquanto choravam, todas aquelas mulheres, as mães dos meninos faziam subir ao céu a melodia mais triste que já se tinha ouvido no mundo desde que mundo é. O choro das mãezinhas se misturou ao canto das aves - assustadas, mães e aves -, ao som dos riachos - assustadas, mães e águas -, e às lágrimas dos céus - assustadas, mães e nuvens - e o dia finalmente se pôs. A retirada dos guerreiros brasileiros foi discreta. O Conde cantava, bebia e chamava à farra, Tragam as putas, as rameiras, 


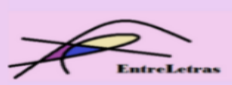

dizia ele, mas os soldados não queriam farra, rameiras ou trago. Nessa noite preferiram relembrar seus filhos, seus irmãos, seus sobrinhos e os meninos que eles mesmos haviam sido. (LABES, 2021, p. 97).

Em uma das passagens do romance voltadas ao tempo presente em que a personagem Udo está no Paraguai, sua interlocutora comenta: "No Brasil, o Dia das Crianças é comemorado em outubro, ouvi dizer. No Paraguay, não. Aqui temos nossa própria data, o 16 de agosto. Para relembrar o massacre de Acosta Nu. O senhor veja como o seu país tem problemas com esta guerra: sequer conseguem pronunciar direito no nome da batalha.” (LABES, 2021, p. 132). Na continuação, revela-se que Campo Grande, como no Brasil muitos denominam a referida batalha, não é tradução para Acosta $\tilde{N} u$ (o campo de Acosta). “Qualquer lugar no Paraguay é um campo grande, se o senhor me permite a explicação" (LABES. 2021, p. 133). O interesse da personagem Udo, como parece indicar o capítulo 9 (uma carta resposta) e em outros trechos do romance, ultrapassa a busca por seu antepassado. Muitas informações sobre o Paraguai de outras épocas e do presente são apontadas especialmente nas partes, espalhadas ao longo da obra, em que essa voz interlocutora assume a narrativa.

Mais um elemento relevante no romance é a fábrica onde praticamente todos os homens das redondezas lá trabalhavam, entre eles, obviamente, as personagens Hubert, Hans e Udo.

\begin{abstract}
A fábrica existiu desde sempre. Antes de chegarem os alemães ao vale, antes de chegarem os portugueses ao Brasil. Talvez Deus tenha construído sozinho, quando estava construindo o Mundo. Os rios da cidade não tinham função que não alimentar os canos da indústria com água limpa e receber o rejeitos coloridos da tinturaria. As árvores, estas foram plantadas e cresceram para no fim alimentarem de lenha as caldeiras. (LABES, 2021, p. 140).
\end{abstract}

Além das relações de trabalho fabril e dos afazeres domésticos, a narrativa passa por várias questões inerentes ao ser humano, aos aspectos individuais e sociais. Para ficar com alguns deles, pode-se mencionar as reuniões entre empresários e políticos e o juiz preocupados em "queimar arquivos" que pudessem relacioná-los ao nazismo (LABES, 2021, p. 150-153), o pastor amigo da família interessado nas possíveis riquezas escondidas no baú cuja existência foi revelada nos últimos dias da personagem Olga, aguçando a curiosidade de personagens e do leitor até as páginas finais do livro (LABES, 2021, p. 86-87), ou o padre que, ao desconfiar das mentiras da personagem Wilhelm na acusação a um homem negro, concluiu que Deus olharia melhor a quem ajuda um viajante e não um escravizado. O padre "por fim repetiu aos homens, em português, o que ouviu, e já não havia quem pudesse impedir que a turba iniciasse o espancamento do escravo, que desde o início dessa conversa manteve-se ajoelhado, mirando o chão.” (LABES, 2021, p. 45).

Romance de histórias, memórias, silêncios e perdas, a palavra surge alucinadamente: 


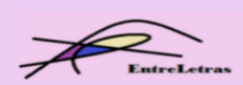

De Pepe ninguém nunca soube, nem mesmo que tivesse existido. O silêncio que carregavam nas costas e a tranquilidade de viverem sempre no presente fizeram de Olga uma moça sem perguntas e de Frieda uma mulher sem o incômodo de respondêlas - pelo menos não enquanto estava lúcida, porque perto do fim da vida contou, sem poder optar, tudo quanto ouvira a respeito do esposo e do sogro, o velho Wilhelm. (LABES, 2021, p. 196).

O que se passou com a personagem Frieda se repetiu com as personagens Olga e Hans que, “de manhã cedo até a noitinha, enquanto falava, ele era outro, um Hans que Anna jamais vira, um homem cheio de palavras, sotaques, gírias, entendido das coisas do mundo, conhecedor de lugares onde nunca esteve. 'A loucura, minha filha, a loucura sempre chega nessa família"”. (LABES, 2021, p. 182). Trata-se de um romance que também grita pelo encontro efetivo entre as pessoas, pelo acesso à educação, pela vida repleta de afetos em que os conhecimentos e as experiências são importantes e devem ser exercitados nas oportunidades de todos os dias.

A leitura de Paraízo-Paraguay leva consequentemente a indagações de como se dá sua relação com a temática da Guerra do Paraguai. Posto nos limites da "palavra armada" expressada na introdução deste trabalho, a obra destaca-se, como foi adiantado mais acima, pela coesão ficcional a partir da experiência, da imaginação e dos eventos históricos. Mais que se preocupar com uma "autópsia" da guerra, com as relações institucionais e diplomáticas, que não deixam de ter sua relevância histórica, social e informativa, tem consciência de que as “pessoas, e não os países, é que sofrem com as guerras. Porque os países são feitos de símbolos. As pessoas é que são feitas de derrotas.” (LABES, 2021, p. 133). Essa é, antes de tudo, a tônica de um romance que faz por merecer a atenção do leitor e dos prêmios possíveis.

\section{Considerações finais}

Nesse estudo, a opção pela análise dos romances históricos Canudos de Antônio Conselheiro (2018) e Paraízo-Paraguay (2019) deveu-se à relevância dos temas abordados e pelo aspecto de atualização das obras relativas a dois temas bélicos latino-americanos que vêm merecendo a atenção de ficcionistas os quais, no conjunto, ajudaram a formar uma espécie de tradição narrativa a respeito da Guerra de Canudos e da Guerra do Paraguai.

A obra de Hélio de Araújo, devedora de autores consagrados como Euclides da Cunha e José Calasans, segue a direção das leituras favoráveis aos sertanejos e críticas às ações republicanas, em consonância - em certa medida, mas por caminhos narrativos diferentes com O pêndulo de Euclides (2009), de Aleilton Fonseca, principal e mais inovadora narrativa canudense escrita desde La guerra del fin del Mundo (1981), do peruano Mario Vargas Llosa. 


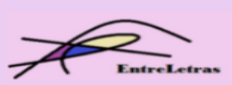

REVISTA ENTRELETRAS (ARAGUAÍNA), V. 12, N. 3, SET./DEZ. 2021 (ISSN 2179-3948 - ONLINE)

A obra de Marcelo Labes parte de considerações historiográficas que tentam se apartar de correntes interpretativas excessivamente "donas da verdade". Também não se restringe ao tempo histórico da guerra, como demarcaram o paraguaio Guido Rodríguez Alcalá em Caballero (1987) e o argentino Zelmar Acevedo Díaz em El piano de Chopin (2017), para mencionar dois entre os grandes romances latino-americanos já escritos. A feitura ampliada de Paraízo-Paraguay em relação ao tema bélico estaria mais próxima ao que fizeram Marco Cremasco em Santo Reis da Luz Divina (2004) e o uruguaio Mario Delgado Aparaín em No robarás las botas de los muertos (2002).

Os romances trazidos para este estudo, por vias e temáticas distintas, convidam o leitor a revisitar dois momentos históricos fundamentais no percurso da história moderna da América Latina. A ficção lança mão dos eventos passados e os recolocam à disposição de quem pode e precisa lembrar que os fatos, a imaginação, a literatura e o olhar crítico são componentes essenciais a quem não pretende se afogar nos mares da ignorância autômata.

\section{Referências}

ACEVEDO DÍAZ, Zelmar. El piano de Chopin. Buenos Aires: Voria Stefanovsky Editores, 2017.

ALBUQUERQUE, Adenilson B. Narrativas canudenses: conflitos além da guerra. Dissertação. (Mestrado em Letras). Cascavel, PR. UNIOESTE, 2013.

ALBUQUERQUE, Adenilson de Barros de. A "palavra armada": ficcionalizações da Guerra Grande (1864-1870). Tese. (Doutorado em Letras). Cascavel, PR. UNIOESTE, 2020.

ALBUQUERQUE, Adenilson de Barros de; FLECK, Gilmei Francisco. Canudos: conflitos além da guerra - entre o multiperspectivismo de Vargas Llosa (1981) e a mediação de Aleilton Fonseca (2009). Curitiba: Editora CRV, 2015.

ARAÚJO, Hélio de. Canudos de Antônio Conselheiro. [e-book]. Petrolina: UNIVASF, 2020.

CREMASCO, Marco. Santo Reis da Luz Divina. Rio de Janeiro: Record, 2004.

CUNHA, Euclides da. Os Sertões: campanha de Canudos. Rio de Janeiro: Francisco Alves, 1987.

DELGADO APARAÍN, Mario. No robarás las botas de los muertos. Montevideo: Punto de Lectura, 2008.

FLECK, Gilmei Francisco. O romance histórico contemporâneo de mediação: entre a tradição e o desconstrucionismo - releituras críticas da história pela ficção. Curitiba: Editora CRV, 2017.

FONSECA, Aleilton. O pêndulo de Euclides. Rio de Janeiro: Bertrand Brasil, 2009. 


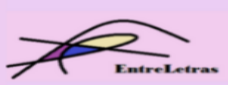

REVISTA ENTRELETRAS (ARAGUAÍNA), V. 12, N. 3, SET./DEZ. 2021 (ISSN 2179-3948 - ONLINE)

FREIRE, Wellington. A condução da guerra em Os Sertões. Feira de Santana: UEFS Editora, 2017.

G1 PETROLINA. Escritor de Petrolina lança romance sobre a Guerra de Canudos. 2018. Disponível em: https://glo.bo/2Yn2ZuF Acesso em: 04 out. 2021.

LABES, Marcelo. Paraízo-Paraguay. Florianópolis: Caiaponte Edições, 2021.

LEÃO, Aroldo Ferreira. Hélio Araújo: o voo e o ressurgimento (Prefácio). ARAÚJO, Hélio de. Canudos de Antônio Conselheiro. [e-book]. Petrolina: UNIVASF, 2020, p. 4-6.

LIMA, Antônia Lúcia. Orelha 2. Hélio Araújo: o voo e o ressurgimento (Prefácio). ARAÚJO, Hélio de. Canudos de Antônio Conselheiro. [e-book]. Petrolina: UNIVASF, 2020, p. 115-116.

RODRÍGUEZ ALCALÁ. Caballero. Buenos Aires: Editorial Sudamericana, 1987.

VARGAS LLOSA, Mario. La guerra del fin del mundo. Barcelona: Seix Barral, 1981.

Recebido em 15 de outubro de 2021. Aceito em 03 de janeiro de 2022. 